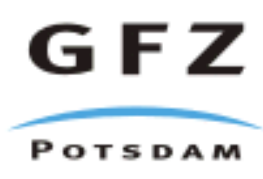

Originally published as:

Weckmann, U., Jung, A., Branch, T., Ritter, O. (2007): Comparison of electrical conductivity structures and 2D magnetic modelling along two profiles crossing the Beattie Magnetic Anomaly, South Africa. - South African Journal of Geology, 110, 2-3, 449-464

DOI: 10.2113/gssajg.110.2-3.449 


\title{
Comparison of electrical conductivity structures and 2D magnetic modelling along two profiles crossing the Beattie Magnetic Anomaly, South Africa
}

\author{
Ute Weckmann and Andre Jung \\ GeoForschungsZentrum Potsdam, Telegrafenberg, 14473 Potsdam, Germany \\ University of Potsdam, Institute of Geosciences, Potsdam, Germany \\ e-mail: uweck@gfz-potsdam.de; andre.jung@gmx.net, \\ Thomas Branch \\ GeoForschungsZentrum Potsdam, Telegrafenberg, 14473 Potsdam, Germany \\ AEON-Africa Earth Observatory Network, University of Cape Town, Rondebosch 7701, South Africa \\ e-mail: Thomas.Branch@explorationservices.co.za, \\ Oliver Ritter \\ GeoForschungsZentrum Potsdam, Telegrafenberg, 14473 Potsdam, Germany \\ e-mail: oritter@gfz-potsdam.de
}

(c) 2007 September Geological Society of South Africa

\begin{abstract}
Two of the Earth's largest geophysical anomalies, the Beattie Magnetic Anomaly (BMA) and the Southern Cape Conductive Belt (SCCB) extend across the southern African continent for more than $1000 \mathrm{~km}$ in an east-west direction. Based on previous electrical and magnetometer array measurements it is believed that both anomalies have a common crustal source with a width of $50 \mathrm{~km}$ represented by serpentinized palaeo-oceanic crust. New two-dimensional (2D) electrical conductivity models along a profile from Prince Albert to Fraserburg outline a narrow ( $2 \mathrm{~km}$ wide), southward-dipping zone of high electrical conductivity in the upper crust below the centre of the Beattie Magnetic Anomaly (BMA). Two-dimensional modeling studies of aero-magnetic data show that simple models that can explain the magnetic signature of the BMA, are not consistent with a narrow conductivity anomaly. Thus a common source for the two anomalies is unlikely. A second magnetotelluric (MT) experiment across the BMA, conducted along a $75 \mathrm{~km}$ profile centred on Jansenville, $350 \mathrm{~km}$ east of the first profile, resolves a sub-vertical and narrow conductivity anomaly below the centre of the BMA. At this location the conductor is reaching deeper to lower crustal levels and is inclined towards the north.
\end{abstract}

\section{Introduction}

The Beattie Magnetic Anomaly (BMA) and the Southern Cape Conductive Belt (SCCB), two of Earth's largest continental geophysical anomalies, extend across the southern African continent in an east-west direction. The BMA was first discovered by Beattie (1909). More than half a century later Gough et al. (1973) reported on measurements using an array of 24 three-component magnetometers that lead to the identification of the $140 \mathrm{~km}$ broad and over $1000 \mathrm{~km}$ long SCCB. Based on the reversal of the vertical magnetic transfer functions at very long periods (> $5000 \mathrm{~s}$ ), the source of the SCCB was previously interpreted to originate in to the middle to lower crust (Gough et al., 1973). Due to the spatial correlation of the BMA and the SCCB, a common source in the form of a $50 \mathrm{~km}$ wide southward dipping sliver of serpentinized palaeo-oceanic crust that reached to depths of $30 \mathrm{~km}$ was suggested to be the cause of these anomalies (e.g. Pitts et al., 1992; Harvey et al., 2001). The location of both anomalies parallel to the assumed tectonic boundary of the Namaqua Natal Mobile Belt (NNMB) and the Cape Fold Belt (CFB) provides the basis for an alternative interpretation in terms of tectonic structures related to the accretion process. Corner (1989), for example, suggested that mineralized thrust zones within the NNMB granitoid basement were a more likely explanation for the anomalies. To resolve structural details of both geophysical anomalies, two modern, high resolution magnetotelluric (MT) experiments were conducted across the Karoo Basin within the framework of the Inkaba yeAfrica project (Figure 1). In March, 2004, MT data along a $150 \mathrm{~km}$ long northsouth profile between Prince Albert and Fraserburg (western profile MT1) were recorded. In November, 2005, a similar experiment was conducted along a $70 \mathrm{~km}$ long profile centred on Jansenville, some $350 \mathrm{~km}$ farther east (eastern profile MT4) (Figure 1). Both lines cross the Phanerozoic Karoo Basin that in turn overlies the Mesoproterozoic granitoid basement of the Natal Namaqua Mobile Belt. The Prince Albert line (MT1) is located above the Namaqua sector of the NNMB and the Jansenville profile (MT4) runs across the Natal sector [Eglington and Armstrong, 2003; Thomas et al., 1992]. The 2D magnetotelluric inversion results of profile MT1 [Weckmann et al., 2007] reveal an electrical image of the NNMB crust with some previously unknown structures. Two very prominent features are a sub-vertical, $\sim 2 \mathrm{~km}$ wide high conductivity anomaly at 7 to $12 \mathrm{~km}$ depth beneath the surface trace of the maximum of the BMA, and a shallow, regionally continuous sub-horizontal 


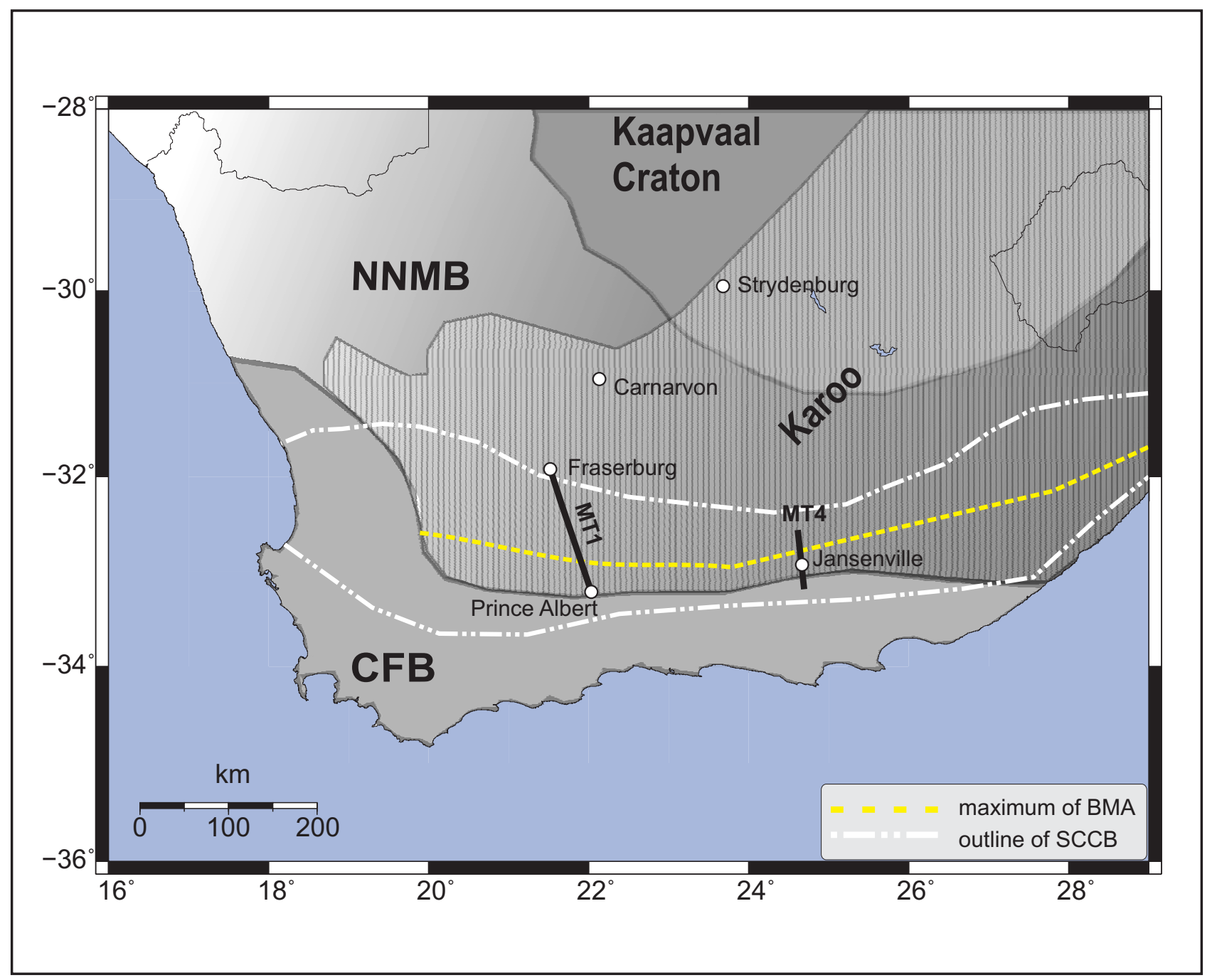

Figure 1. Simplified terrane map of southern Africa showing the Archean Kaapvaal Craton, the Mesoproterozoic Namaqua Natal Mobile Belt (NNMB) and the upper Paleozoic Cape Fold Belt (CFB). A large region is covered by Paleozoic-Mesozoic sediments and igneous rocks of the Karoo Basin (shaded). The axis of the Beattie Magnetic Anomaly (BMA) and the boundaries of the Southern Cape Conductive Belt (SCCB; Figure 12 in de Beer et al. (1982)) are marked by a dashed line and a dot-dashed line, respectively. The locations of the MT profiles MT1 and MT4 are shown by solid black lines. The western line extends from Prince Albert to Fraserburg, the eastern one is centered around Jansenville.

band of high conductivity in the Karoo sedimentary basin that can be related to a 50 to $70 \mathrm{~m}$ thick pyriticcarbonaceous marker horizon in the Whitehill Formation (see also Branch et al., 2007). The inversion results by Weckmann et al. (2007) suggested that the conductivity anomaly below the maximum of the BMA is too small to explain the observed SCCB; however, the anomalously high electrical conductivities of the entire NNMB crust could explain the observations by the magnetometer array study. In this study we report on a comparison of both profiles (MT1 and MT4) and explore if a common source of the BMA and SCCB is supported by the electrical conductivity results. In addition to the MT data, a $100 \mathrm{~km}$ long seismic near-vertical reflection line (Lindeque et al., 2007) was carried out along the western profile (MT1), and wide angle reflection/refraction measurements (Stankiewicz et al., 2007) as part of an on-shore/off-shore experiment (Parsiegla et al., 2007) were conducted along both transects.

\section{Geological setting}

The two MT profiles are separated by $350 \mathrm{~km}$ in an eastwest direction. The surface geology does not change significantly across this distance. The entire area of interest is underlain by 5 to $6 \mathrm{~km}$ thick Paleozoic sediments of the Cape and Karoo Supergroups.

The main Karoo basin has been modeled as a foreland basin formed in response to the formation of the CFB to the south (Cole, 1992; Cloetingh et al., 1992; Johnson et al., 1997; Catuneanu et al., 1998), during crustal shortening associated with subduction and accretion of the palaeo-Pacific plate beneath the Gondwana plate (Hälbich, 1983; 1993; Cole, 1992; de Wit and Ransome, 1992). In the study area, the Karoo Basin starts with glacial sediments of the Dwyka Group ( 600 to $700 \mathrm{~m}$ thick) that are overlain by the postglacial Ecca Group, comprising black shales of the Prince Albert Formation $(\sim 150 \mathrm{~m})$ and carbonaceousand pyritic-shales of the Whitehill Formation (50 to 


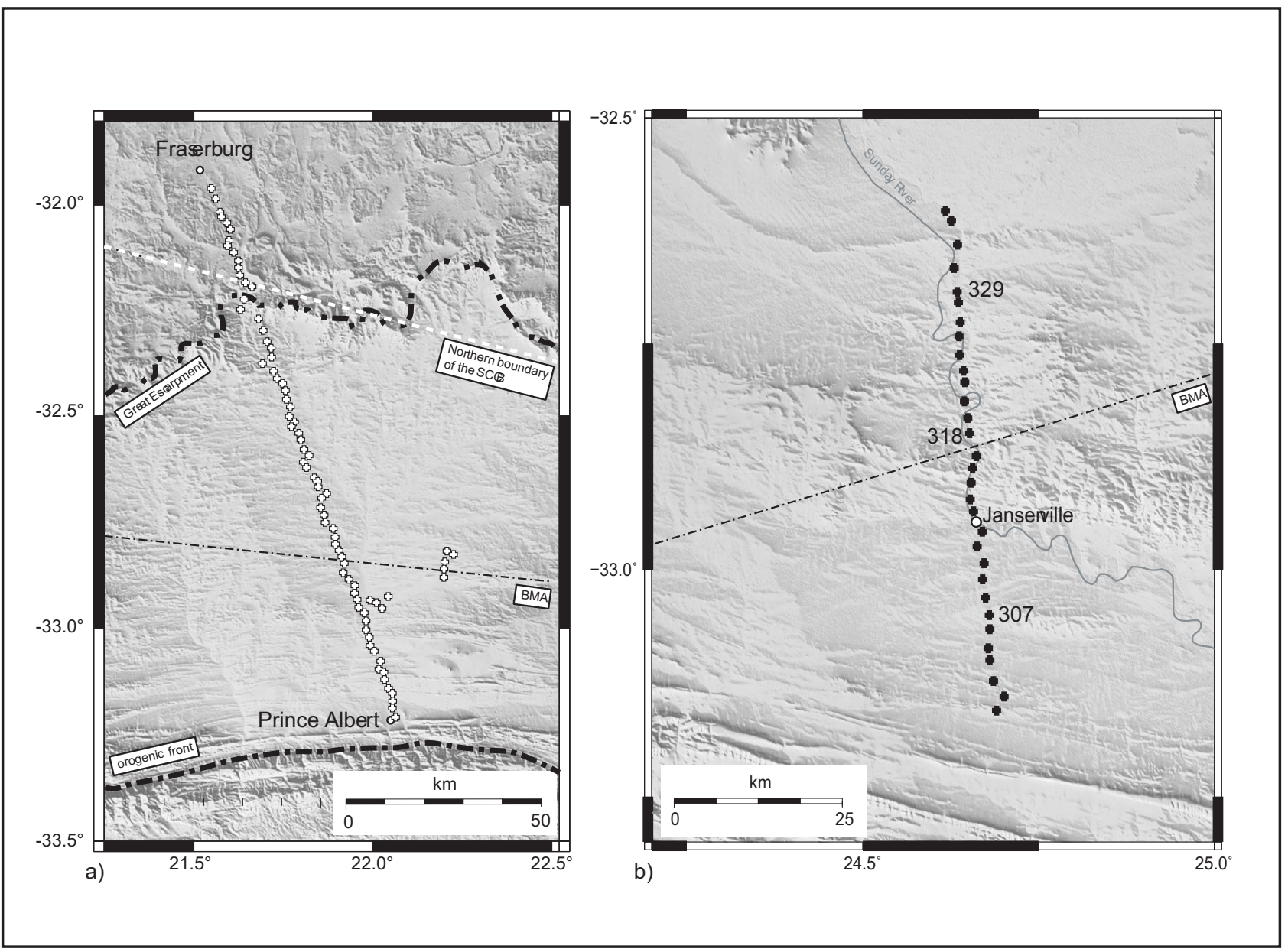

Figure 2. (a) Location of 82 MT sites deployed along a $150 \mathrm{~km}$ long profile from Prince Albert to Fraserburg. Nine additional sites near the surface trace of the BMA (Beattie Magnetic Anomaly) were located to the East of the main profile to avoid crossing of the DC railway system. The black dashed line in the north delineates the location of the Great Escarpment. South of Prince Albert, the black dashed line marks the surface expression of the tectonic front of the CFB. (b) Location of 31 MT sites deployed along a $70 \mathrm{~km}$ long profile centered on Jansenville.

$70 \mathrm{~m}$ ) of the Ecca Group (Cole, 1992) (for a summary of the stratigraphy and lithologies, see Branch et al. (2007). The lower Ecca Group is followed by thick massive sandstones and thin shales of the upper Ecca and lower Beaufort Groups (Cole, 1992; Johnson et al., 1997). Overlying this is a 3 to $4 \mathrm{~km}$ thick sequence of terrestrial fluvial deposits, dominated by sandstones and lesser shales (Upper Beaufort). The total thickness of the Karoo Basin sequences ranges between ca. 5 to $6 \mathrm{~km}$. Underlying the Karoo Basin are the siliciclastic rocks of the early Paleozoic Cape Basin, the lowermost sections of which comprise predominantly thick mature sandstones and quartzites (e.g. Cole, 1992, and references therein). Drilling shows that some sequences of the Cape Supergroup also underlie the Karoo sediments in the southern study area, but that they thin rapidly northwards where they onlap the high grade Mesoproterozoic basement of the NNMB. The precise northern edge of the Cape Basin is not known, but the Cape Supergroup sediments preserved at the northern extremity of the study area are thin to absent.

In our study area, the sediments of the Karoo and the Cape Basin unconformably overlie the high-grade gneisses of the NNMB. These gneisses are exposed along the eastern and western parts of South Africa in the Natal and Namaqualand (Bushmanland and Richtersveld subprovinces), respectively. Both regions were affected by high-grade metamorphism and deformation between 1.0 to $1.1 \mathrm{Ga}$ (Jacobs et al., 1993). However, there are distinct geological and isotopic differences (crustal model ages and geochronology) between the Natal and the Namaqualand, and a number of separate terranes have now been identified (Jacobs et al., 1993; Thomas et al., 1994; Eglington and Armstrong, 2003). The Namaqualand metamorphic rocks were derived from older basement (1.3 to $1.8 \mathrm{Ga}$ ), whereas the Natal rocks comprise of a mosaic of eastwest elongated volcanic/plutonic arc terranes dating around 1.1 to $1.4 \mathrm{Ga}$ (Thomas et al., 1994; Eglington and Armstrong, 2003).

\section{Magnetotelluric data across the BMA}

The MT data of the western transect MT1 were collected along a profile between Prince Albert and Fraserburg, crossing the BMA in its entire width and the northern $100 \mathrm{~km}$ segment of the SCCB (Figures 1 and 2a). Data 

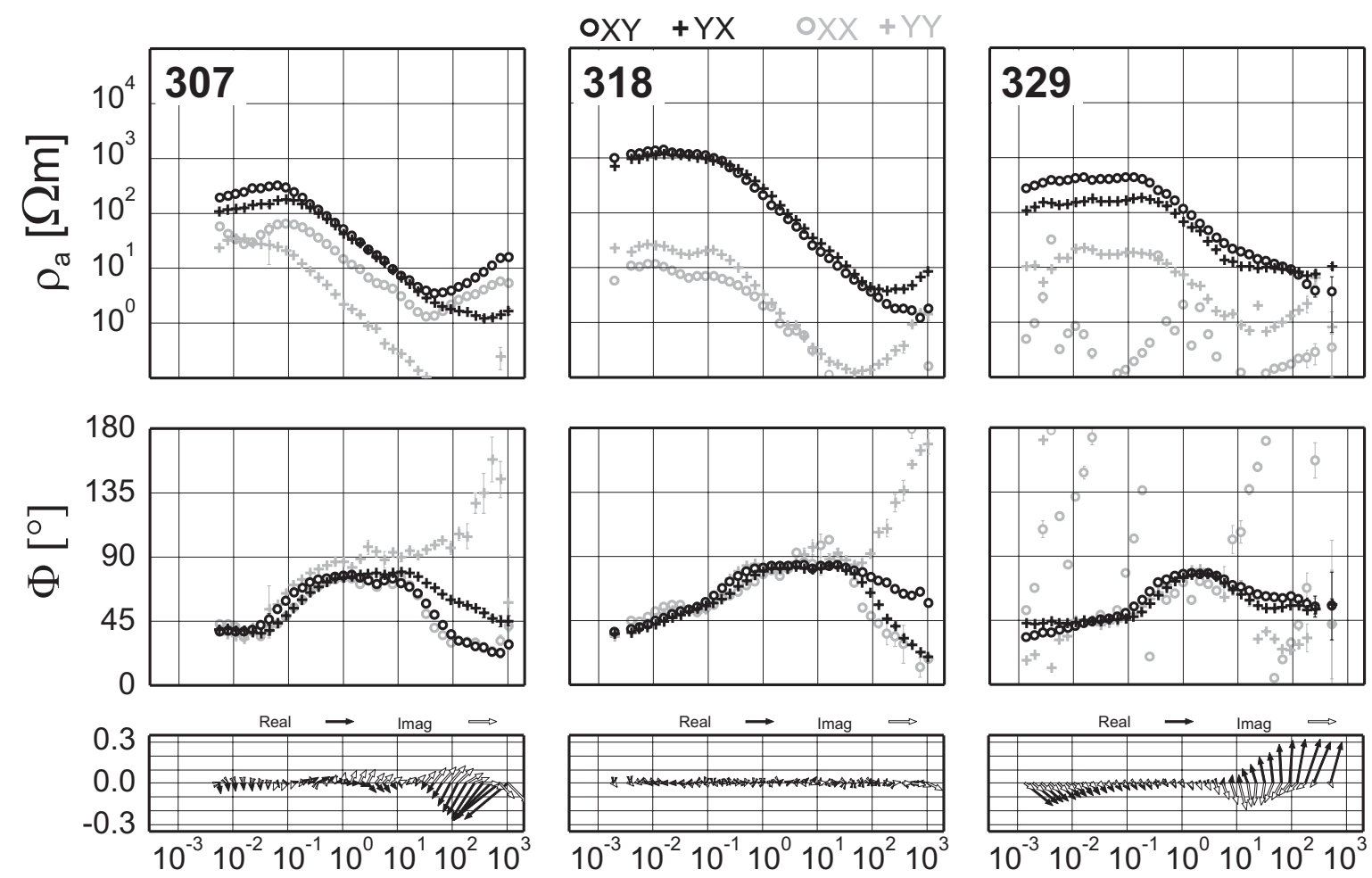

a) Period $[\mathrm{s}]$

b) Period [s]

c) Period [s]

Figure 3. Off-diagonal and diagonal components of apparent resistivity (upper panel), phase (mid panel) and induction vectors (lower panel; Wiese convention) of three example sites (in a geographic coordinate system: $x \triangleq$ geographic north, $y \triangleq$ geographic east). (a) Site 307 is representative of the area south of the BMA. (b) Site 318 is located near the maximum of the BMA and (c) site 329 is located in the northern section of profile MT4.

analysis and 2D inversion of this profile are described in Weckmann et al. (2007). Along the eastern profile MT4, centred around Jansenville, (Figure 2b) we acquired 5-component MT data at 31 broad band stations in a period range from $0.001 \mathrm{~s}$ to $1000 \mathrm{~s}$ using GPS synchronized S.P.A.M. MkIII (Ritter et al., 1998) and CASTLE broadband instruments. Metronix MFS05/06 induction coil magnetometers and non-polarizable $\mathrm{Ag} / \mathrm{AgCl}$ telluric electrodes were used to record natural electric and magnetic field variations. The data were processed according to Ritter et al. (1998) and Weckmann et al. (2005). In Figure 3, we show apparent resistivities and phase diagrams, which are derived from the MT impedance tensor, and induction vector plots. The three sites presented are marked in Figure $2 \mathrm{~b}$ and are representative of larger areas along profile MT4.

The impedance tensor data are shown in a

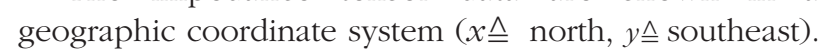
The xy- and yx-component (off-diagonal components) of the apparent resistivity and phase curves of site 307 in Figure 3(a) vary smoothly and consistently with period. The general trend of the apparent resistivity curves indicates a change from resistive $\left(\mathrm{T}<10^{-1} \mathrm{~s}\right)$ to more conductive $\left(10^{-1} \mathrm{~s}<\mathrm{T}<10^{2} \mathrm{~s}\right)$ to resistive structures $\left(\mathrm{T}>10^{2} \mathrm{~s}\right)$ with increasing period. The diagonal elements of apparent resistivity and phase (in light grey colours in Figure 3) are smaller when compared with the off-diagonal elements. The real (black) and imaginary (open) induction vectors are presented in Wiese convention (Wiese, 1962) in the lower panel. In Wiese convention the real part of the induction vector tends to point away from the conductive side of a lateral conductivity contrast. They show small vectors for periods $<20 \mathrm{~s}$; at the longest periods $(>50 \mathrm{~s})$, the real vectors are oriented in southwesterly direction with imaginary vectors pointing predominantly anti-parallel. Site 318 (Figure 3b) is located on the east-northeast striking maximum of the BMA. Here, both off-diagonal components have steeply decreasing apparent resistivity curves from $\sim 1000 \Omega \mathrm{m}$ at $0.005 \mathrm{~s}$ to $\sim 1 \Omega \mathrm{m}$ at $1000 \mathrm{~s}$. However, phase values below $45^{\circ}$ at the longest periods (widening induction space) indicate increasing resistivity. At site 318, the induction vectors vanish for the entire period range. Site 329 (Figure 3(c)), to the north of the BMA, yields apparent resistivity curves with a more resistive subsurface. In contrast to site 307 the longest induction 


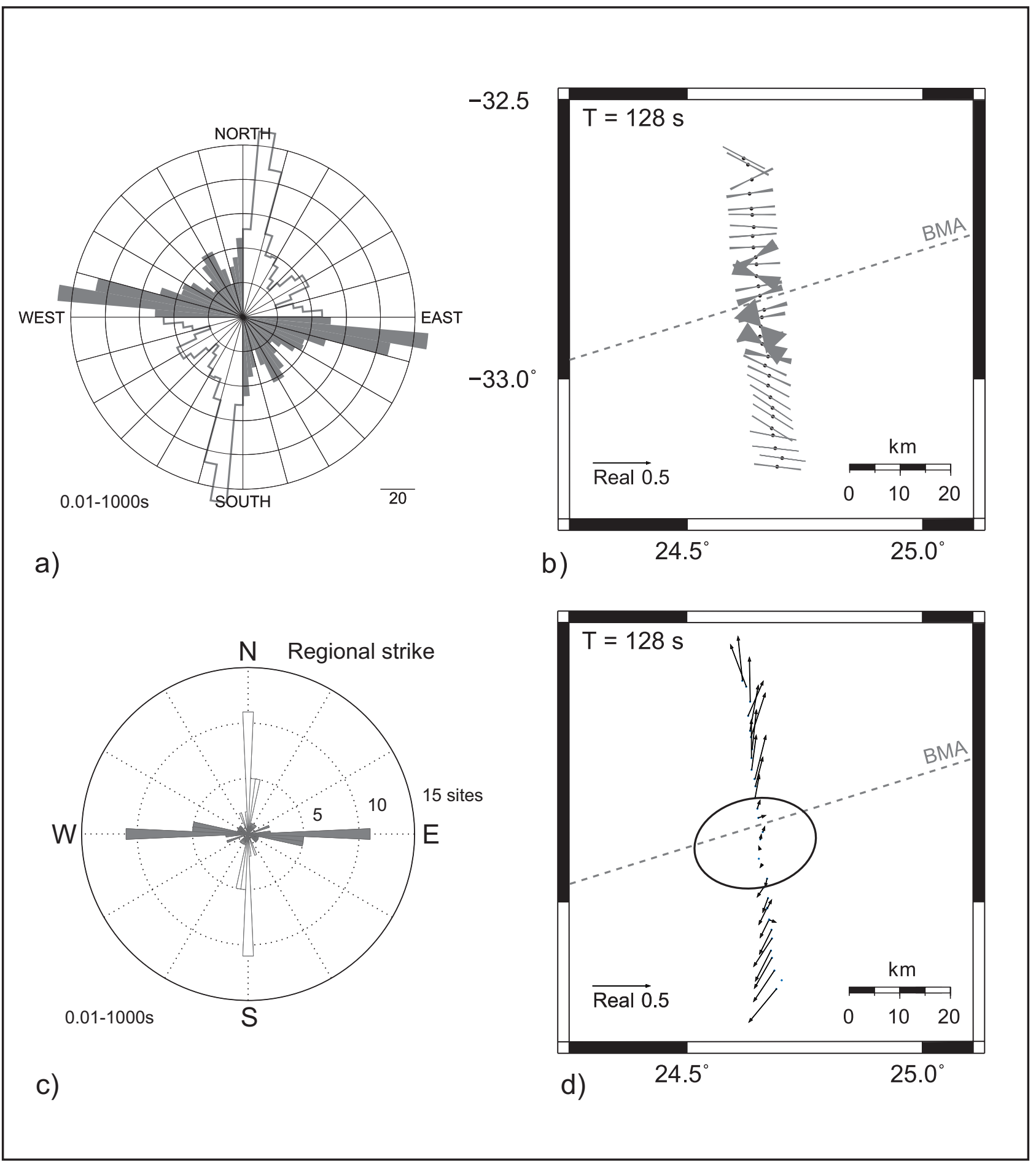

Figure 4. (a) Rose diagrams of phase sensitive strike estimates for all sites and periods of MT4 in the range from $0.1 \mathrm{~s}$ to $1000 \mathrm{~s}$. The data indicate a predominantly east-southeast strike direction. (b) Map of phase sensitive strike directions (Bahr, 1988) for a period of $128 \mathrm{~s}$. The dashed line indicates the centre of the BMA. Sites in close vicinity to the BMA show strike directions coincident with the strike of the BMA, whereas strike directions of sites farther away slightly deviate from this direction. (c) Rose diagram of regional strike direction obtained by the tensor decomposition after Becken and Burkhardt (2004). For each site a regional strike direction for the entire period range from $0.1 \mathrm{~s}$ to $1000 \mathrm{~s}$ is computed. This analysis indicates an east-west strike direction for the majority of the sites. (d) Map of real induction vectors (Wiese convention) for a period of $128 \mathrm{~s}$. The induction vectors show a reversal of the real induction vectors. This indicates an eastwest striking zone of high electrical conductivity, which correlates with the location of the maximum of the BMA. 

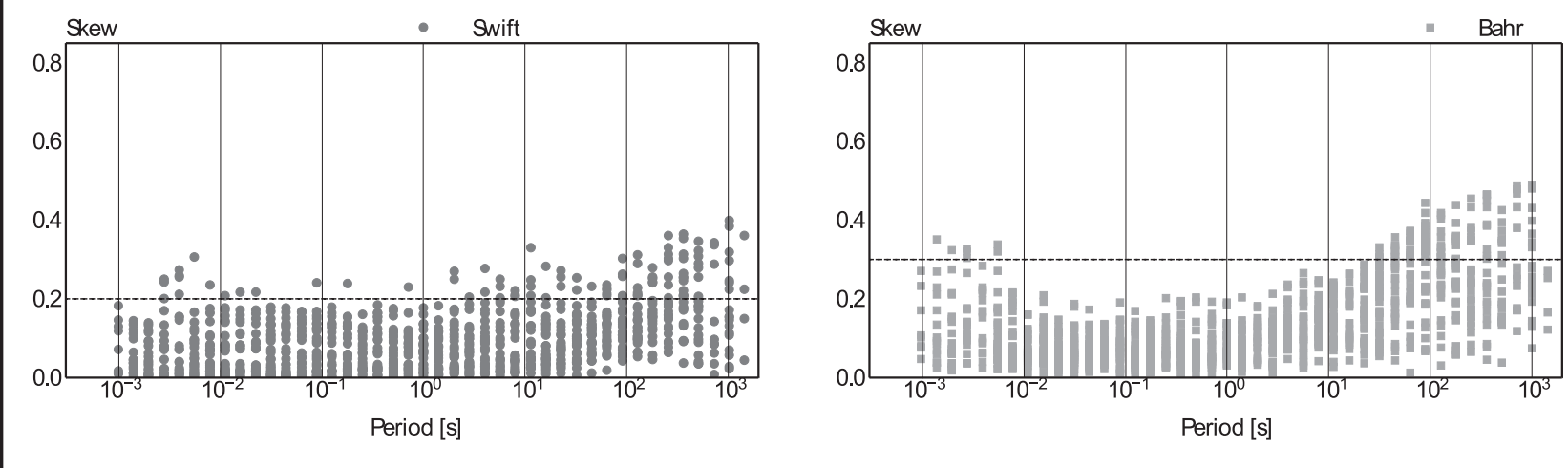

Figure 5. (a) Swift (Swift, 1967) and (b) Bahr (Bahr, 1988) skew values for all sites along the Jansenville profile (MT4). We observe skew values above the empirical threshold of 0.2 (Swift) and 0.3 (Bahr) only at periods $>100$ s.

vectors at long periods point northwards. This reversal of the induction vectors indicates a high conductivity zone in the middle part of the profile.

In order to evaluate if the MT data are compatible with a 2D interpretation, the dimensionality of the electromagnetic fields and the geo-electric strike direction must be determined. We applied tensor decomposition schemes after Bahr (1988), Swift (1967) and Becken and Burkhardt (2004). Figure $4 \mathrm{a}$ shows a rose diagram of phase sensitive strike directions (Bahr, 1988) estimated for all sites and periods between $0.1 \mathrm{~s}$ and $1000 \mathrm{~s}$. The majority of strike estimates fall in a range of $95^{\circ}$ to $105^{\circ}$ with a maximum of $95^{\circ}$ to $100^{\circ}$ (open areas indicate a $90^{\circ}$ ambiguity, which is inherent in the analysis). The strike direction of the BMA in the vicinity of Jansenville is $\sim \mathrm{N} 70^{\circ} \mathrm{E}$. A map of strike directions after Bahr (1988) for a period of $128 \mathrm{~s}$ (Figure $4 \mathrm{~b}$ ) reveals changes of the strike direction along the profile. Sites closest to the maximum of the BMA show the same strike direction as the BMA (indicated by the dashed line). Further to the south, an eastsoutheasterly strike direction dominates while to the north of the BMA an eastward strike direction can be observed. The deviation of strike directions along the profile may be due to off-profile structures, like sedimentary basins farther to the southeast (e.g. the Gamtoos Basin). Alternatively, the strike direction of the magnetic anomaly and the axis of the SCCB could differ slightly in this region.

The regional strike direction obtained from the analysis using the method of Becken and Burkhardt (2004) is depicted in Figure 4c. This method uses the polarization states of the electromagnetic fields to express the dimensionality of the impedance tensor in terms of an ellipticity parameter. A single site/multifrequency analysis of the entire data set confirms a predominant east-west strike direction.

The map of the induction vectors (Figure $4 \mathrm{~d}$ ) for the same period of $128 \mathrm{~s}$ also reveals some deviations from a pure two-dimensional case. The reversal of the induction vectors indicates a conductive feature beneath the surface trace of the BMA. South and north of this conductor we observe induction vectors pointing away, whereas sites on top of it show decreasing vector length. South of the BMA we observe a southwest component of the induction vectors, which could be attributed to the above-mentioned sedimentary basin. In summary, the analysis indicates a strike direction of approximately $95^{\circ}$ to $100^{\circ}$ (Bahr) and $90^{\circ}$ (Becken and Burkhardt), the profile is oriented at $-5^{\circ}$, and the strike direction of the BMA is $70^{\circ}$. As a compromise we rotated the MT data by $24.5^{\circ}$ into a geographic coordinate system $\left(0^{\circ}\right)$ by taking into account that the field setup was in the geomagnetic coordinate system and that the magnetic declination in the area of interest was $-24.5^{\circ}$ at the time of the survey. This implies that for further $2 \mathrm{D}$ modeling the xy-component of the MT impedance tensor represents the E-polarization data with electric currents flowing along strike and the yx-component represents the B-polarization with current systems perpendicular to strike.

The dimensionality structure of the electromagnetic fields can be regarded as an indicator for the dimensionality structure of the subsurface. It can be estimated from the (phase sensitive) skewness of the MT impedance tensor (Swift, 1967; Bahr, 1988). Figure 5 shows skew values after (a) Swift and (b) Bahr for all sites and over the entire period range. The dashed lines indicate empirically determined thresholds of 0.2 (Swift) and 0.3 (Bahr) above which a 2D assumption cannot be maintained (Bahr, 1991). For most of the data the phase sensitive skew values are below 0.2 and 0.3 , respectively, so that a two-dimensional interpretation is adequate to explain the most relevant features in the data. This assumption is supported by the tensor analysis developed by Becken and Burkhardt (2004), which leads to very small ellipticity parameters for the majority of sites and frequencies.

The observed MT data (separated into E- and B-polarization) and the vertical magnetic transfer function are shown as pseudo-sections in Figure 6, together with the calculated responses of the $2 \mathrm{D}$ 

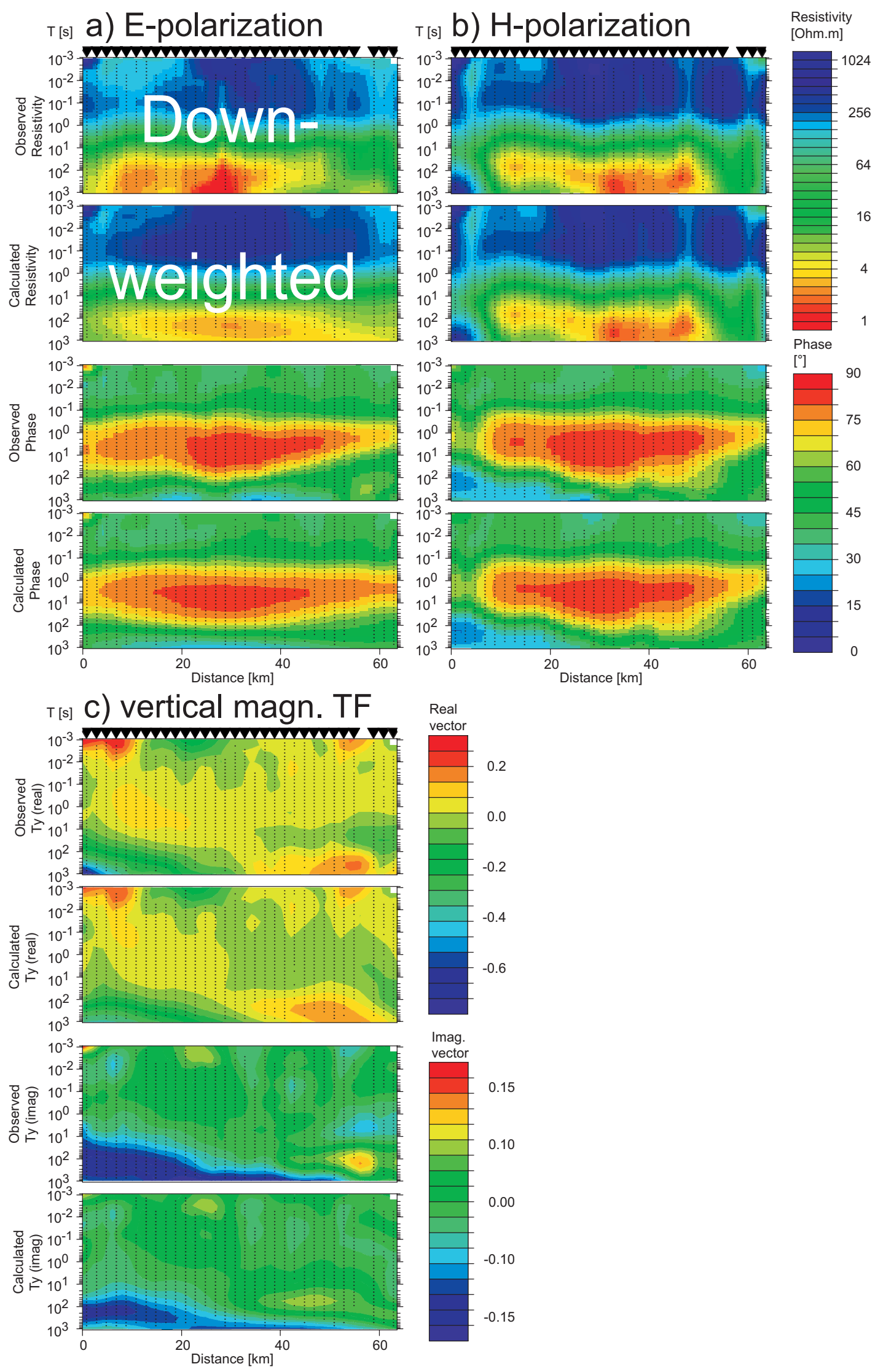

Figure 6. Pseudo-sections of measured and calculated apparent resistivity, phase and vertical magnetic transfer function of all sites along profile MT4. E-polarization apparent resistivities were down-weighted (200\% error floor) and only the phase information of this component was used for the inversion. 
a) 2D inversion model: eastern profile (MT4)
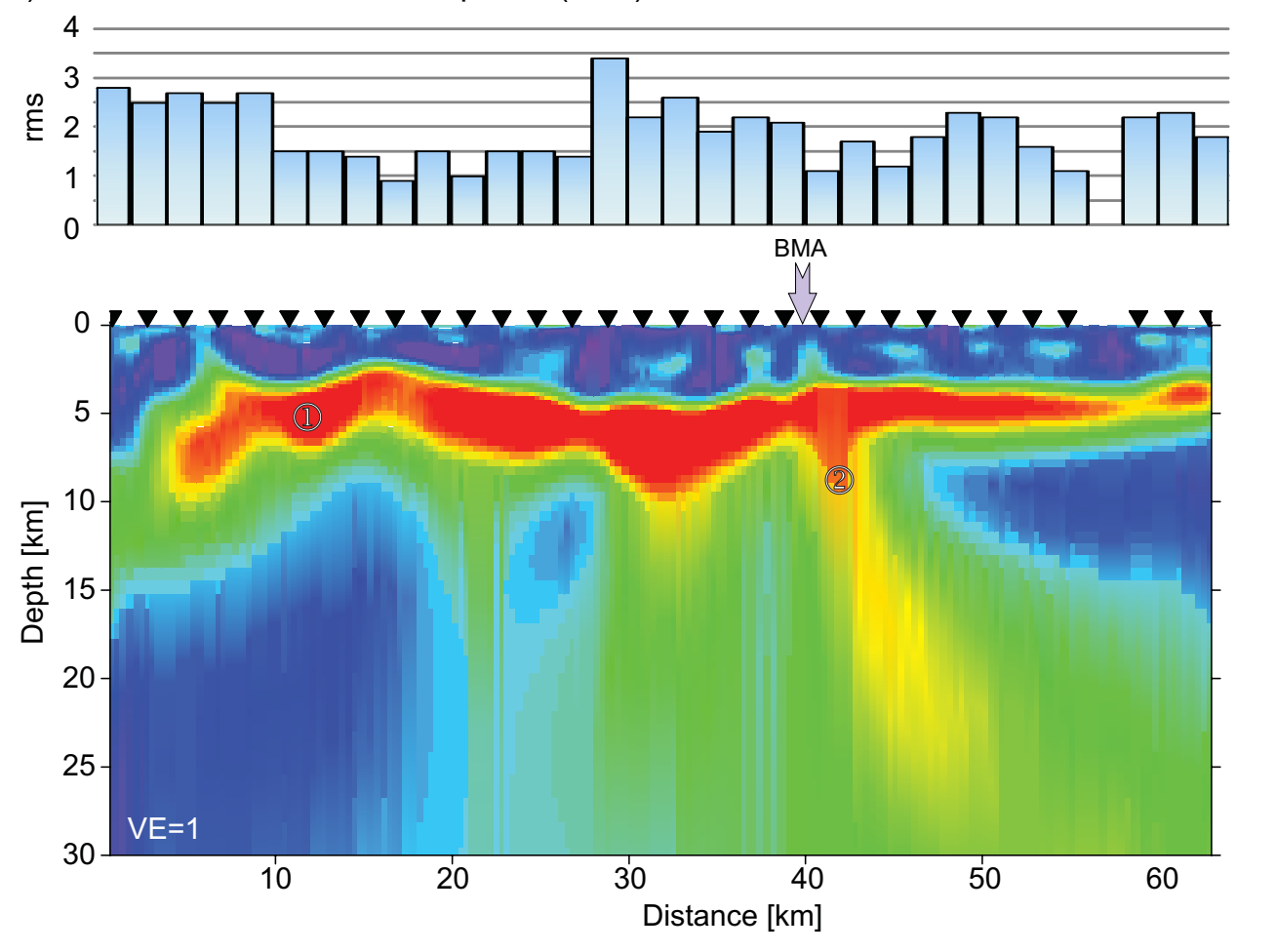

b) $2 \mathrm{D}$ inversion model: western profile (MT1)

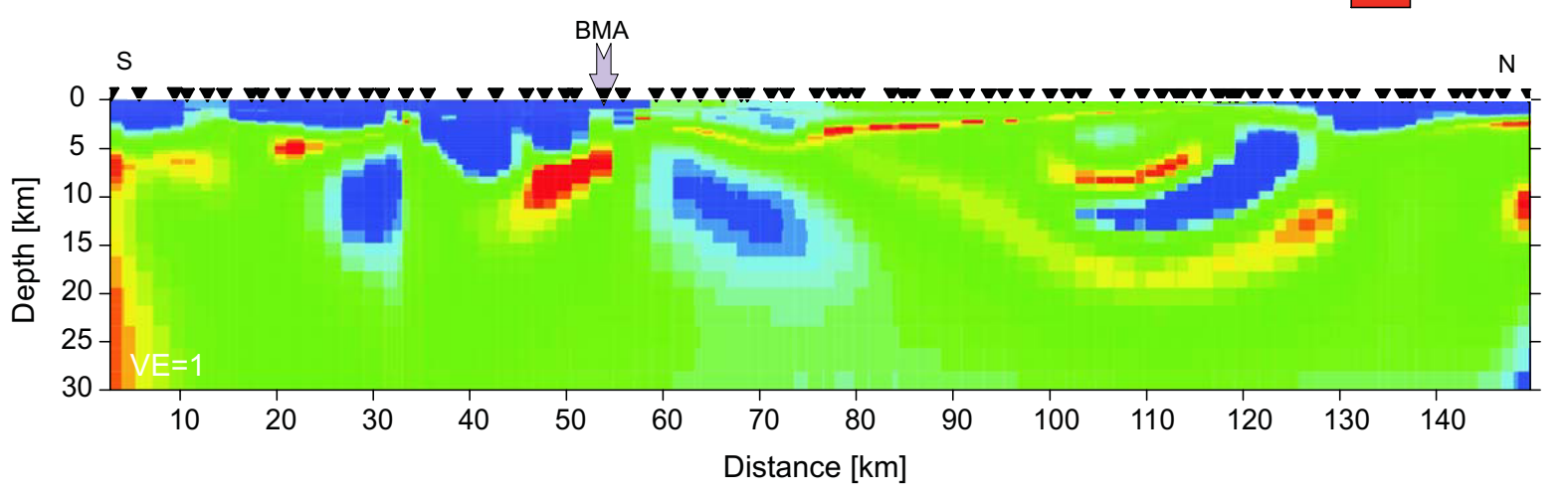

Figure 7. (a) Electrical conductivity model along profile MT4 (lower panel of (a)) derived from 2D inversion and data misfit at each site (upper panel of (a)). Site locations are indicated by black triangles. The maximum of the BMA is depicted by grey arrows. Red and yellow colours indicate zones of high conductivity. An extensive zone of resistivities $\leq 2 \Omega \mathrm{m}$ comprises of two anomalies: a sub-horizontal band in the upper $10 \mathrm{~km}$ (1) and a sub-vertical feature going down to $\sim 25 \mathrm{~km}$ depth (2). Both anomalies seem to be connected. (b) The $2 \mathrm{D}$ inversion model along the western profile is taken from Weckmann et al. (2007). The most prominent conductivity anomalies are beneath the maximum of the BMA and the shallow sub-horizontal and of high conductivity in the upper $5 \mathrm{~km}$.

inversion model (see Figure 7). The apparent resistivities of the E-polarization (Figure 6a) and the B-polarization (Figure 6b) show high values of approximately 500 to $1000 \Omega \mathrm{m}$ for periods ranging from 0.001 to $1 \mathrm{~s}$ consistently along the profile. For longer periods $>1 \mathrm{~s}$ the apparent resistivities decrease to values of $1 \Omega \mathrm{m}$. A consistent behaviour is found for the observed phases, which show high values for the period range of $\sim 1 \mathrm{~s}$.
The y-component of the vertical magnetic transfer function mainly shows a reversal at long periods, which can also be seen in the induction vector plot in Figure $4 \mathrm{c}$. The reversal is also indicated in the transition from red to green colours for long period data in the pseudo-section plot of the vertical magnetic field (Figure 6c). 


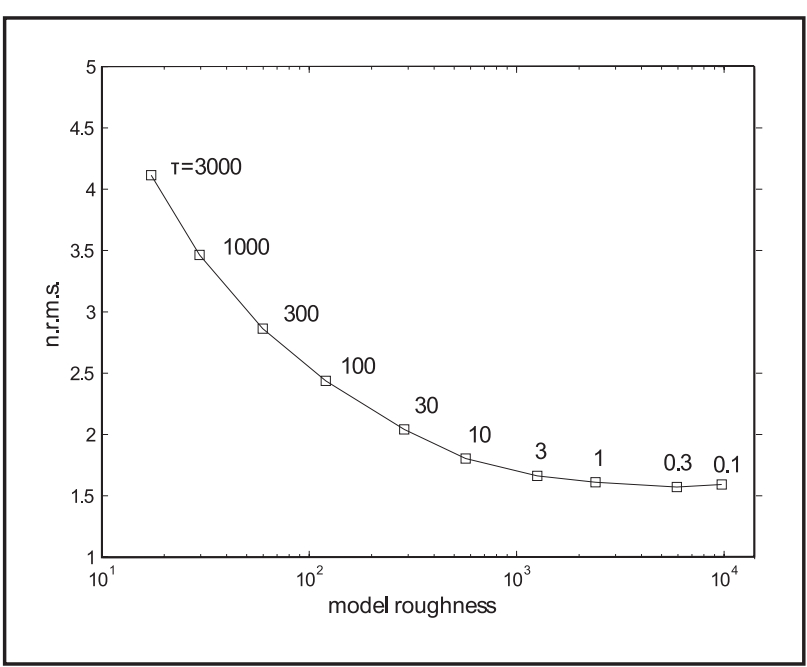

Figure 8. Trade-off curve (L-curve) between data residuals (as normalized rms) and model roughness using a weighted integral of the Laplacian squared of the model computed for the regularization parameter $\tau$ ranging from 0.1 to 3000. For all subsequent modeling studies we used $\tau=30$.
Comparison of the 2D inversion results from the eastern (MT4) and western profile (MT1)

The 2D inversion models in Figure 7 are the results of a minimum structure, non-linear conjugate gradient 2D inversion algorithm (RLM2DI) after Rodi and Mackie (2001) (http://www.geosystem.net). For the inversion of the MT data from the eastern profile (Figure 7a), E- and B-polarization data are jointly inverted as a first step, starting from a homogeneous half space of $100 \Omega \mathrm{m}$. In a second step, this model was used as a starting point for a combined E- and B-polarization plus vertical magnetic field inversion. Preset error bounds of 5\% for B-polarization apparent resistivity and 200\% for E-polarization apparent resistivity and $0.6^{\circ}$ for the phases of both polarizations were applied. Larger error floors were assigned to the apparent resistivity data, in particular to the E-polarization to avoid problems with static shift effects and off-profile features. In contrast to the E-polarization, the inversion algorithm is able to account for static shift effects in the B-polarization. For

\section{D inversion model with "tear zone"}
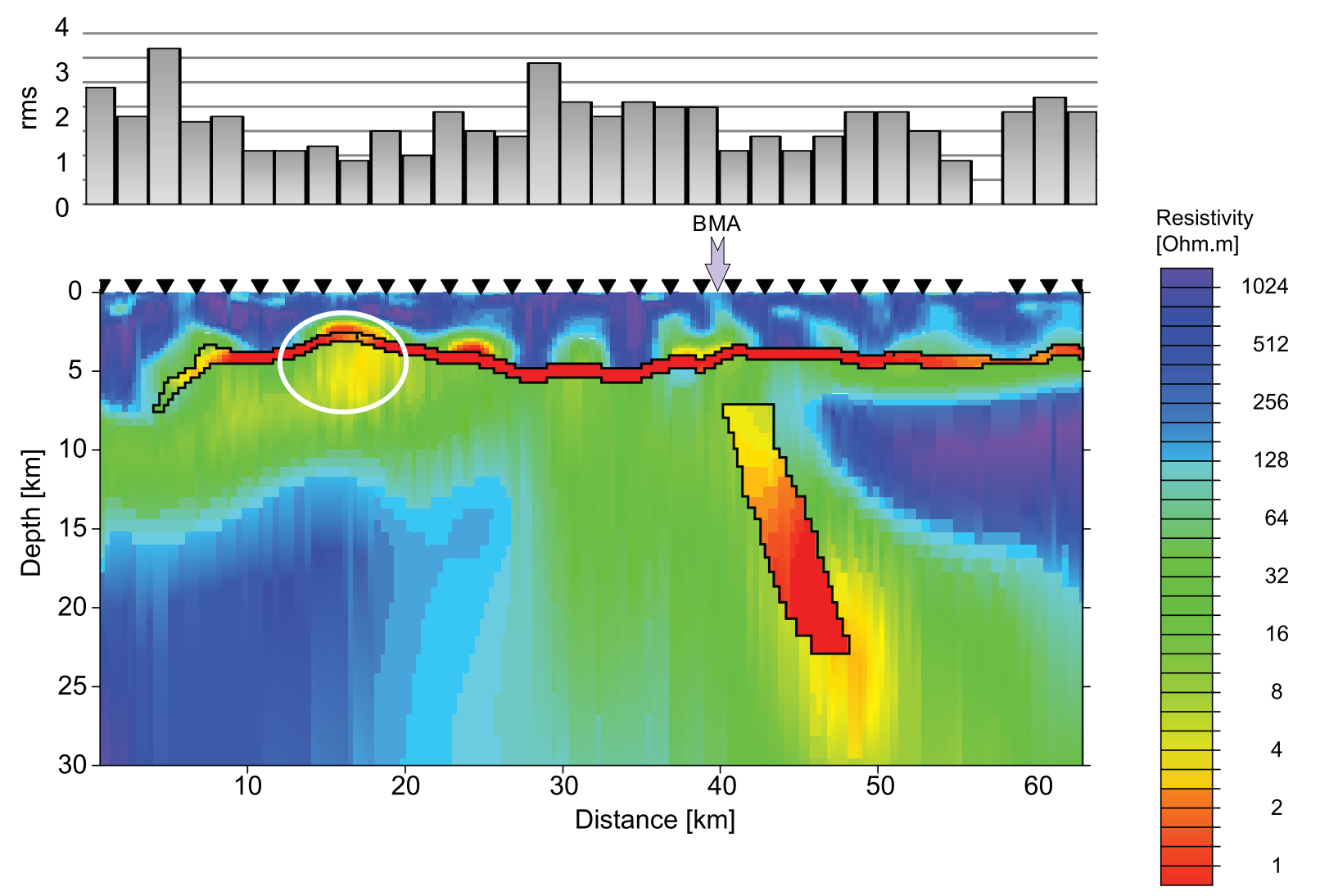

Figure 9. Electrical conductivity model along profile MT4 obtained from the 2D inversion with additionally defined "tear zones" (lower panel), shown as black outlines: Across those regions the inversion algorithm (regularization) does not penalize sharp conductivity contrasts. This option is particularly useful for resolution tests, e.g. to test for the minimum thickness of the shallow, high conductivity layer, its connection to or isolation from the deeper sub-vertical conductor and the depth extend of the latter. At profile kilometer 17 (marked with a white circle) we observe that the MT data are not in agreement with the thin "tear zone", because the inversion introduces a zone of high conductivities beneath this layer. The upper panel shows the rms misfit for each site, which has improved compared to Figure 7. 


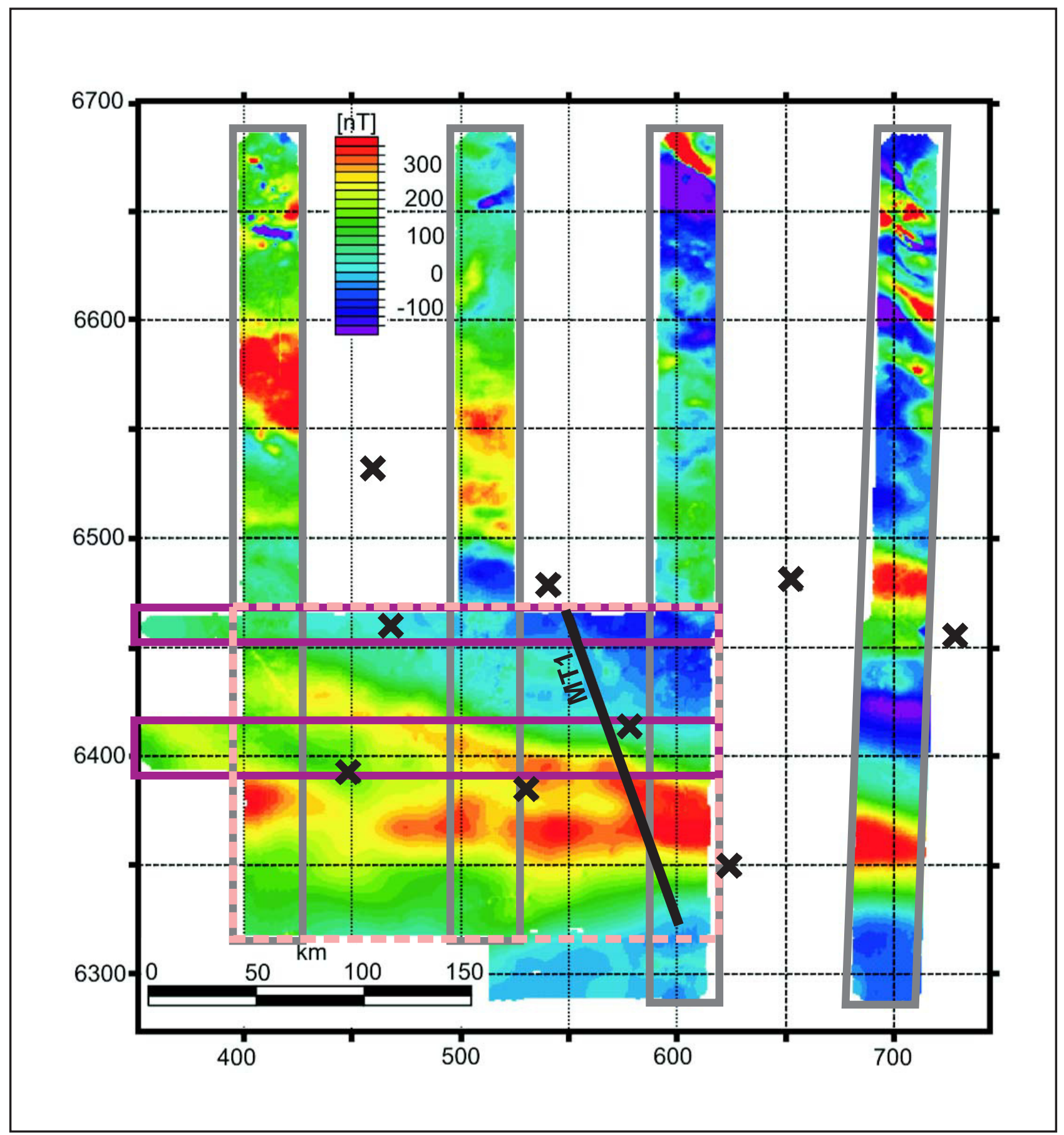

Figure 10. Map of the aero-magnetic data provided by the Council for Geosciences, Pretoria. The data set includes four long, north to south running surveys with 17 to 22 north to south oriented flight lines with $1 \mathrm{~km}$ separation (grey outlines), one east to west running survey with 16 flight lines in an east to west direction plus two east to west lines farther north (purple outlines). The rectangular array (pink dashed line) was covered by a grid of flight lines in north to south and east to west direction with a spacing of $10 \mathrm{~km}$. The approximate location of profile MT1 is indicated by the black line. Black crosses mark existing deep boreholes in the Karoo Basin.

the vertical magnetic field error bounds were set to 0.01 . In order to find an optimal regularization parameter $\tau$ for the inversion we tested different $\tau$-values for the inversion. Figure 8 displays the trade-off curve (L-curve) between data residuals and roughness for $\tau$ ranging from 0.1 to 3000 . At the knee of this curve the model norm and the residuals are sensitive to changes of $\tau$. In our case, $\tau$ values between 30 and 100 are acceptable and as a compromise we used $\tau=30$ for our modelling studies.
In the resistivity image in Figure 7 , red and yellow colours indicate zones of high electrical conductivity, whereas dark and blue colours show zones of low electrical conductivity (high resistivity). The misfit between model response and MT is 1.9 without and 2.3 including the vertical magnetic field. The model shows one extensive zone of high electrical conductivities $\leq 2 \Omega \mathrm{m}$, which comprises of a sub-horizontal layer at 3 to $10 \mathrm{~km}$ depth and a sub-vertical feature beneath the 


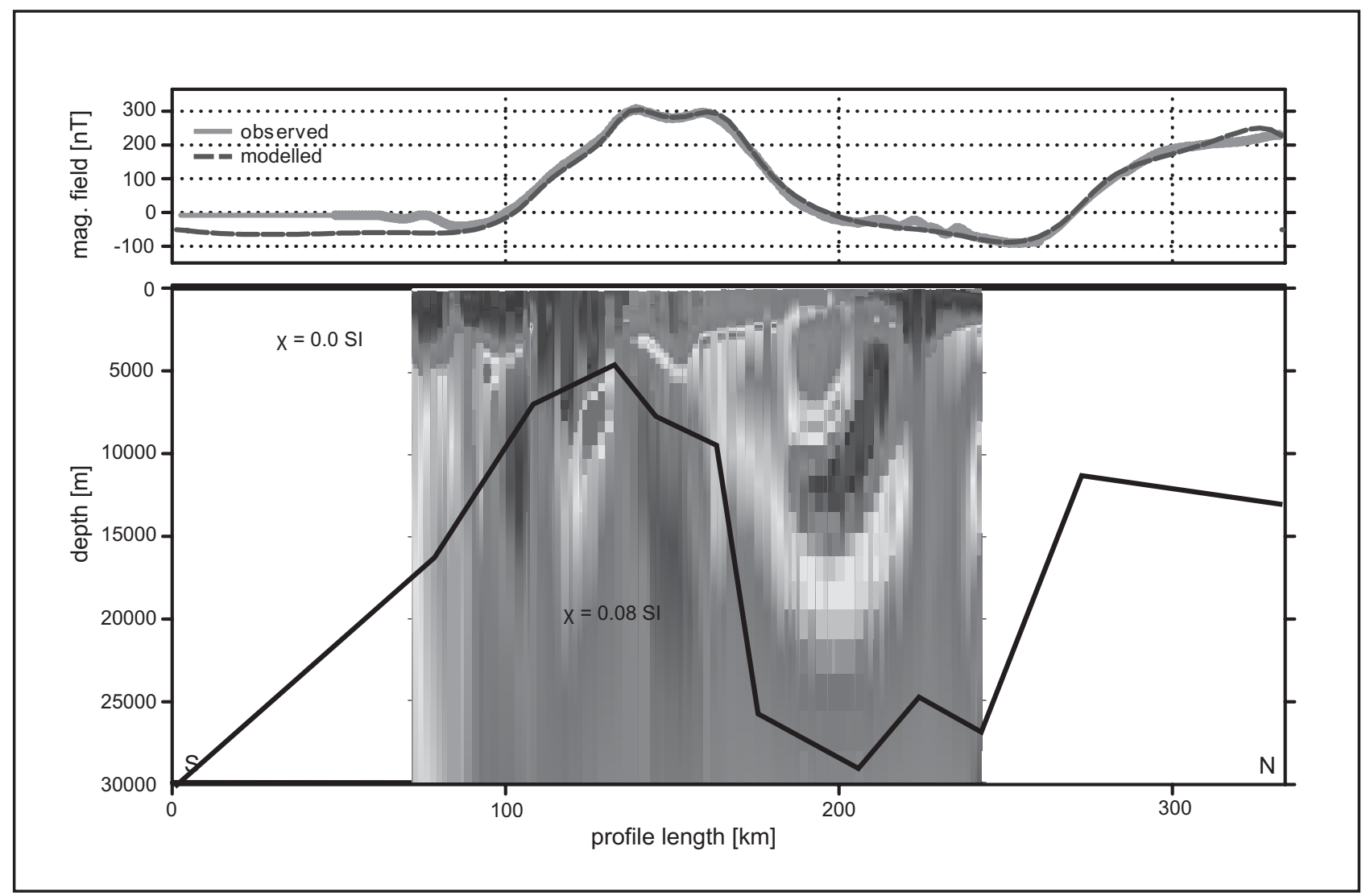

Figure 11. Simple 2D magnetic model to explain the magnetic signature of the BMA. The upper panel shows the observed magnetic field data (solid line) and the calculated response (dashed line) along the MT profile. The lower panel shows the location and extension of an anomalous magnetic body with an induced susceptibility of 0.08 SI superimposed on the MT model. The background susceptibility is set to $0.0 \mathrm{SI}$.

surface trace of the BMA extending to depths of approximately $25 \mathrm{~km}$ depth. The model suggests furthermore that both anomalies are connected. The upper crustal section $(<\sim 3 \mathrm{~km})$ of the model shows high resistivities up to $1000 \Omega \mathrm{m}$.

Comparison of the 2D inversion results of profile MT1 (Weckmann et al., 2007) (Figure 7b) and profile MT4 (Figure 7a) reveals similarities and differences. The model MT1 includes an extensive, thin sub-horizontal band of high conductivity $(2 \Omega \mathrm{m})$ in the upper $5 \mathrm{~km}$ of the Karoo Basin. The conductivity model of profile MT4 shows a similar, but distinctly thicker (ca. $5 \mathrm{~km}$ ) layer. In both models we observe a conductivity anomaly beneath the maximum of the BMA. However, shapes, inclinations and extensions are different. Along MT1, the anomaly beneath the BMA extends from a depth of approximately 5 to $10 \mathrm{~km}$ and dips to the south. The structure is not connected to the near-surface, conductive sub-horizontal structure. Along MT4, $350 \mathrm{~km}$ farther east, the sub-vertical conductor appears connected to the conductive layers of the Karoo sequences and is steeply inclined towards the north, reaching into the middle to lower crust $(\sim 25 \mathrm{~km})$.

Weckmann et al. (2007) interpreted the conductivity anomaly associated with the BMA as a crustal-scale shear zone in the NNMB, and the sub-horizontal upper crustal high conductivity layer was associated with the overlying Whitehill Formation of the Karoo sequence that consists of carbonaceous black shales and pyrite. Branch et al. (2007) report on impedance spectroscopy measurements of rock samples collected in a nearby deep borehole, which generally supports this interpretation. Because there is no evidence that glacial sediments of the underlying Dwyka Group have high electrical conductivities, a thickness of up to $5 \mathrm{~km}$ for conductive layers in the Karoo Basin along MT4 is unlikely. Similarly questionable is a connection of the sub-horizontal sedimentary layers to the sub-vertical crustal-scale conductivity anomaly as found along this profile. In MT models, the thickness of a shallow conductive layer is typically poorly constrained; it is possible that this layer is thinner but more conductive. The same holds true for the depth extend of the sub-vertical conductive structure.

In order to test the resolution and reliability of the conductivity anomalies along profile MT4, a series of 2D constrained inversions were undertaken. Figure 9 shows a model study to constrain the thickness of the shallow high conductivity layer and its depth extent. This can be achieved by defining so-called "tear zones", an option for a 2D smooth inversion devised by Rodi and Mackie (2001). Typically, the smooth inversion algorithm penalizes sharp conductivity contrasts, in order to obtain 

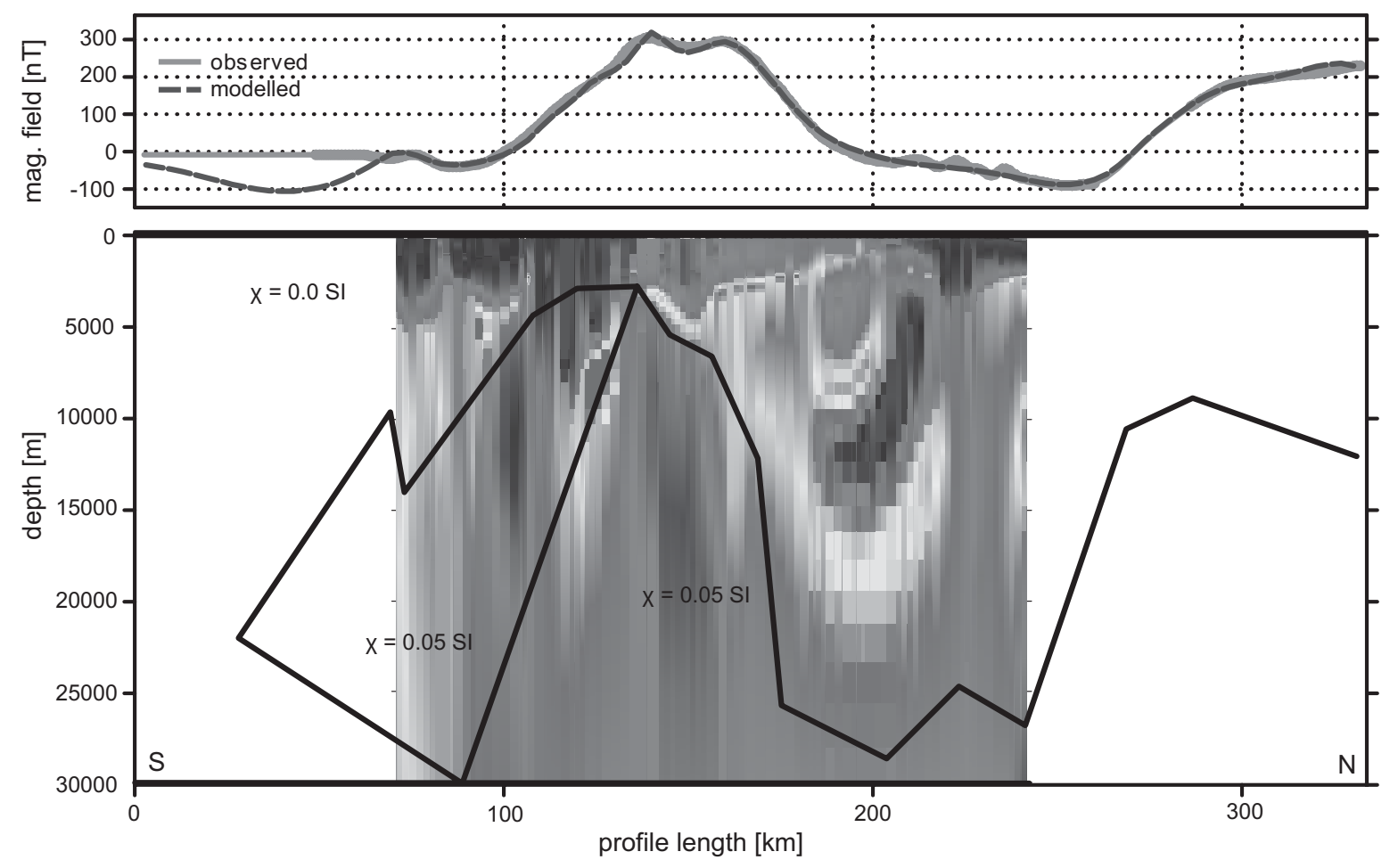

Figure 12. Alternative $2 \mathrm{D}$ magnetic model: In this case, the anomalous magnetic body is modeled with an induced susceptibility of 0.05 SI (black lines; lower panel). The magnetic body is cut at the position of the conductivity anomaly (see background MT model) and the gap is filled with material with an induced susceptibility of 0.0 SI. This model study shows that an intersection of the magnetic body, maybe by a large shear zone as interpreted on the basis of the MT model, is in agreement with the MT and the magnetic results

smooth minimum structure models. In nature, however, different lithologies and thus different electrical conductivities can be juxtaposed. With a "tear zone" we define regions in the model for which sharp conductivity contrasts between neighbouring grid cells are not penalized; however, the resistivity values of the affected grid cells can be changed during inversion.

We started with the final, unconstrained 2D inversion model shown in Figure $7 \mathrm{a}$ and introduced two "tear zones". These are outlined in black on Figure 9. The first "tear zone" comprises of the top $750 \mathrm{~m}$ of the sub-horizontal high conductivity band. The grid cells below were set to the background resistivity of $30 \Omega \mathrm{m}$ (green colour). This procedure reduced the thickness of the sub-horizontal conductor by a factor of four. As a side effect, the sub-vertical anomaly is now disconnected from the overlying conductive layer. The general form of the sub-vertical conductor was used to construct a second "tear zone" (extending down to a depth of $23 \mathrm{~km}$ ). The depth to the top of the sub-vertical conductor was varied in several inversion runs. Based on the data fit it was finally set to $7 \mathrm{~km}$.

The inversion result in Figure 9 (lower panel) was retrieved after additional 50 iterations with the inclusion of both "tear zones". The final rms for the "tear zone" model is 1.8. A comparison of the single-site rms values of the model in Figure 7a, (upper panel) with those of the "tear zone" model (Figure 9 upper panel) shows that the rms has improved at each site. Most parts of the model outside the defined "tear zones" were not affected. However, we clearly see that the inversion algorithm now maintains the thin conductive layer with a sharp conductivity contrast at its bottom without worsening the data fit. As a consequence, resistivity values of up to $0.3 \Omega \mathrm{m}$ are reached. Such extremely low resistivity values can be explained by an electronic conduction mechanism or very hot and saline fluids. Impedance spectroscopy investigations on borehole samples (Branch et al., 2007) show almost perfect (metallic) conductivities on some pyrite rich rock samples. At profile kilometer 17 (marked with a white circle) we observe that the MT data are not in agreement with such a thin and shallow layer, because the inversion requires a zone of high conductivities beneath the "tear zone" to fit the data.

A very important result of this study is that a connection between the shallow conductive layer and the sub-vertical conductor is not required by the MT data. This is in agreement with the assumption that the sub-vertical anomaly beneath the centre of the BMA is confined to the basement of the NNMB.This is also consistent with the stratigraphy of the Karoo Basin in which the more resistive Dwyka Formation underlies the conductive Whitehill formation. The "tear-zone" 
inversion results also indicate that the lower boundary of the sub-vertical conductor at $\sim 23 \mathrm{~km}$ depth is not sufficient to explain the data. The inversion result shows that a zone of high conductivities penetrates even farther down. This is a clear indication that the conductivity anomaly beneath the centre of the BMA is a feature that likely extends to lower crustal depth. The crustal thickness along profile MT4 varies between 41 and $43 \mathrm{~km}$ (Stankiewicz, personal communication, 2007). Further resolution tests confirm that the sub-vertical conductivity anomaly is inclined to the north, because a southward dipping structure dramatically worsens the rms misfit ( $r m s>3.8)$.

\section{Magnetic data description and modelling}

The aim of the magnetic modelling is to test if both geophysical anomalies, the BMA and the SCCB, have a common source. The aero-magnetic data along profile MT1 were supplied by the Council for Geoscience, Pretoria, South Africa. The magnetic lines were flown in the early 1980's; the compiled data set contained the information on flight path and altitude together with magnetic total-field variations.

For modelling purposes four long, north to south running surveys with 17 to 22 north-south oriented flight lines with $1 \mathrm{~km}$ separation, one east-west running survey with 16 flight lines in an east-west direction and a grid of flight lines in north-south and east-west direction with a spacing of $10 \mathrm{~km}$ were used (Figure 10). Corrections for different flight altitudes were applied to derive a consistent array of measurements for $100 \mathrm{~m}$ altitude. The orientation and intensity of the background (inducing) magnetic field were assigned on the basis of geomagnetic field parameters for the year of the survey. The external magnetic field for the region was assumed with a magnetic declination of $-25.792^{\circ}$, an inclination of $-53.442^{\circ}$ and a total intensity of $25,818 \mathrm{nT}$. Given the large time frame of the survey, these values vary by $\pm 0.5^{\circ}$ for declination and inclination and $\pm 50 \mathrm{nT}$ for the total intensity. The residual magnetic map was projected onto the MT profile (see Figure 10) and interpolated using an interpolation radius of $5 \mathrm{~km}$ and a spline weight of 5 .

The 2.5D magnetic forward modelling module, based on the Rasmussen and Pedersen (1979) method, within the WinGLink software package was applied for our modelling studies (http:// www.geo-system.net). The 2.5D forward problem is formulated similarly to the $2 \mathrm{D}$ case, but a finite extension along the strike is assumed. This option was not used in our case as the BMA with an extension of more than $1000 \mathrm{~km}$ length can be regarded as infinite.

Due to the instability of magnetic minerals in oxidizing environments, the magnetization of sediments is usually weak compared with the magnetization of crystalline basement. In this case, crystalline basement is equivalent to the magnetic basement, being defined as the uppermost occurrence of rocks carrying a significant magnetization. The rock type or composition of the material that causes the magnetic anomaly is unknown. Corner (1989) suggested magnetite enrichment of a granitic basement caused by influx of water along low angle thrust faults. De Beer et al. (1982) speculated that an accumulation of oceanic lithospheric rocks, e.g., serpentinite, could cause the magnetic anomaly. In both scenarios, we would expect higher magnetite content.

Rocks carry induced magnetization proportional to the present main field, as well as remnant magnetization independent of the present field. Without knowledge of the ratio between the remnant and the induced magnetization and the direction of the remnant magnetization, it is not possible to separate remnant from induced magnetization (Maus and Haak, 2003). Generally, the direction of the remnant magnetization will not be parallel to the direction of the present magnetic field. Such remnant magnetization has been measured only for rocks of Quaternary and Late Tertiary age (Gerovska et al., 2007). Pre-Tertiary rocks with normal and reverse magnetization have been discovered, and their magnetization direction differs considerably from that of the current magnetic field (Blackett, 1956). It is therefore common practice for firstorder studies to assume homogenously magnetization by induced magnetism. Magnetic signatures which cannot be explained by this approach are attributed to remnant magnetization.

Modeling only the induced part of the magnetization can result in an over- or underestimation of the size of the magnetic body depending of the direction of the remnant magnetization. Since it is unlikely that the remnant magnetization of a body in the NNMB is exactly in the same direction as the current day magnetic field, we can assume that the vector of the remnant magnetization is oriented obliquely to the vector of the induced orientation. The size of a body consisting solely of induced magnetization would then be underestimated.

One of the simplest models fitting the magnetic data is depicted in Figure 11. The upper panel shows the observed and calculated magnetic field values. The lower panel contains the outlines of a homogeneously magnetized body superimposed on the electrical conductivity model of MT1 (Figure 7a). The background magnetic susceptibility is set to 0 SI, whereas the susceptibilities used for the magnetic bodies vary between 0.05 SI and 0.08 SI. They are in the mid to lower range of values possible for serpentinite (0.025 to 0.125 SI; after Guo et al. (2004)) or granites. Previous magnetic models by Pitts et al. (1992) employed lower susceptibility than those used in this study. This simple model supports that the BMA is caused by an anomalous magnetic body of at least 100 to $150 \mathrm{~km}$ width. Subsequent tests including magnetic bodies with varying remnant magnetization suggest that the minimum possible width of a magnetic body is approximately $50 \mathrm{~km}$ (Quesnel, personal communication, 2007). 
The magnetic anomaly in Figure 11 is located at a depth of ca. $5 \mathrm{~km}$ and extends down to $30 \mathrm{~km}$. The depth extend of magnetic bodies is controlled by the Curie temperature, above which no magnetization of rocks is sustained. Several studies of the depth of the Curie point suggest a depth range of 30 to $35 \mathrm{~km}$ for old continental crust (Shive et al., 1992, and references therein), such as the NNMB. This magnetic modeling study shows that a relatively thin magnetic body, e.g. less than $2 \mathrm{~km}$ wide, cannot explain the observed magnetic response. Although this first-order model does not account for rock composition or amount of remnant magnetization, it implies that a common source for both geophysical anomalies is unlikely.

In order to obtain the observed magnetic response of the BMA, we need an anomalous magnetic body of 100 to $150 \mathrm{~km}$ width. On the other hand, our favoured interpretation of the narrow conductivity anomaly beneath the BMA is in terms of graphite enrichment along shear planes (Weckmann et al., 2007). Figure 11 suggests that the anomalous magnetic body encompasses both high resistive zones adjacent to the high conductivity anomaly (see Figure 7). This observation may indicate that the magnetic anomaly actually correlates with the resistive area in the conductivity image. As the high resistive area is intersected by the conductivity anomaly beneath the maximum of the BMA, the magnetic body would also be truncated. This scenario was tested with the second model shown in Figure 12. The susceptibility of the anomalous magnetic body was changed slightly, but within the range suggested for serpentinite. The main difference is now a fault, cutting through the body with the same inclination as the conductivity anomaly. This model also fits the observed magnetic field data. This suggests that a shear zone cutting through an extensive magnetic body is consistent with the electrical and magnetic observations.

\section{Discussion and Conclusion}

Sections through MT1 and MT4 (Figures 7 and 9) provide relatively consistent MT images of the crust in the NNMB. In both conductivity sections we observe a continuous sub-horizontal band of high conductivity in the upper $5 \mathrm{~km}$ of the Karoo sedimentary basin. Already in the 1960's, a layer of high electrical conductivity was identified by in situ borehole measurements within the Whitehill Formation of the Lower Karoo (Cole and McLachlan, 1994). A more detailed investigation on the electrical conductivity of rock samples is reported on by Branch et al. (2007). The MT data from two profiles in the NNMB confirm that the Whitehill Formation is regionally very consistent in thickness, and can be traced across the southern Karoo Basin. The correlation of the high conductivity band and Whitehill Formation reveals that black carbonaceous shales and pyrite in the Karoo Basin are the cause of the shallow and subhorizontal high-conductivity anomaly. The bottom of this sub-horizontal high conductivity layer lies well above the unconformity between the Karoo and underlying basements, and less than $5 \mathrm{~km}$ from surface in most regions. This is consistent with the results of the seismic reflection experiment and the wide-angle reflection/refraction profile reported in elsewhere in this volume (Lindeque et al., 2007; Stankiewicz et al., 2007).

The second prominent conductivity anomaly beneath the centre of the BMA is clearly defined in both profiles. This feature appears as a steeply dipping structure in the NNMB basement and has a width of $\sim 1$ to $2 \mathrm{~km}$. For profile MT1, Weckmann et al. (2007) interpret the high conductivities as a mineralized crustalscale shear zone. Fossil shear zones become visible with MT in presence of graphite enrichment on shear planes as observed in the Damara Belt in Namibia (Ritter et al., 2003; Weckmann et al., 2003). The interpretation of such a relatively thin crustal scale shear zone is contrary to the interpretation of the BMA as a $50 \mathrm{~km}$ wide tectonic sliver of serpentinized oceanic crust (Pitts et al., 1992). The latter interpretation was motivated by the attempt to explain the magnetic response of the BMA and the spatial correlation of the SCCB due to a common source. Although serpentinite is a candidate for a magnetic anomalous source, modern electrical conductivity measurements on serpentinite reveal it as a poor electrical conductor (Airo and Loukola-Ruskeeniemi, 2004). Our magnetic modelling studies support the existence of an 100 to $150 \mathrm{~km}$ broad and $25 \mathrm{~km}$ deep reaching magnetic source, but are not consistent with such narrow conductivity anomalies found in both profiles beneath the centre of the BMA. The width of the anomalous magnetic body suggests a correlation with the resistive zones adjacent to the high conductivity anomaly; a feature seen in both conductivity models. The narrow zone of high electrical conductivity could be caused by a mineralized shear zone, cutting through the magnetic source.

The depth extent and the inclination of the subvertical conductor between profile MT1 and MT4 differ. Along profile MT4 we have clear evidence that the northward dipping conductor continues into crustal depth greater than $25 \mathrm{~km}$. This is in contrast to the south dipping anomaly along the western profile that is confined to the middle and upper crust. At this point we speculate that differences in the orientation of tectonic structures of the Namaqua sector in the west (north directed thrusting) and the Natal sector in the east (south directed thrusting) could be the cause for differences in the orientation of the deep MT anomalies. In the Natal sector of the NNMB, major shear zones have been identified that separate four or more tectonic terranes of different crustal character. Interestingly, shear zones constituting the terrane boundaries in Natal appear to be flanked by magnetic anomalies (Thomas et al., 1992).

\section{Acknowledgments}

TB would like to thank the Council for Geoscience, Pretoria, South Africa, and in particular Edgar Stettler for making the magnetic data available to us. Field work in 
South Africa was funded by the GeoForschungsZentrum Potsdam. We thank the Geophysical Instrument Pool Potsdam for providing the MT equipment. This experiment would not have been possible without the dedicated field and logistic support of Rod Green; and the generous permission of the local farmers for access to their land. We also appreciate the help of Albert Alchin, Jana Beerbaum, Marc Green, Stefan Hiemer, Martin Homann, Juliane Hübert, Frohmut Kloess, Ulrich Kniess, Tshifi Mabidi, Shaun Moore, Carsten Müller, Stefan Rettig, Manfred Schüler, Jacek Stankiewicz, Helena van der Merwe, Wenke Wilhelms, Tamara Worzewski for their assistance in the field. UW was supported by the Emmy Noether fellowship of the German Science Foundation DFG. We would like to thank Arne Hoffmann-Rothe, Alan Jones and Maarten de Wit for helpful comments. This is Inkaba yeAfrica contribution number 17 .

\section{References}

Airo M.L. and Loukola-Ruskeeniemi K. (2004), Characterization of sulfide deposits by airborne magnetic and gamma-ray responses in eastern Finland, Ore Geology Reviews, 24, 67-84.

Bahr K. (1988), Interpretation of the magnetotelluric impedance tensor: regional induction and local telluric distortion, Journal of Geophysics., 62, 119-127.

Bahr K. (1991), Geological noise in magnetotelluric data: a classification of distortion types, Physics of the Earth and Planetary Interior, 66, 24-38.

Branch T., Ritter O., Weckmann U., Sachsenhofer R.F. and Schilling F. (2007), The Whitehill Formation - a high conductivity marker horizon in the Karoo Basin., South African Journal of Geology, 110, 465-476.

Beattie J. (1909), Report of the magnetic survey of South Africa, Royal Society of London, Cambridge University Press, United Kingdom.

Becken M. and Burkhardt H. (2004), An ellipticity criterion for magnetotelluric tensor analysis, Geophysical Journal International, 159, 69-82.

Blackett P. M. S. (1956), Lectures on rock magnetism, The Weizmann Science Press of Israel, Jerusalem.

Catuneanu O., Hancox P. and Rubidge B. (1998), Reciprocal flexural behaviour and contrasting stratigraphies: a new basin development mode for the Karoo retroarc foreland system, South Africa, Basin Research, 10, 417-439.

Cloetingh S., Lankreijer A., de Wit M. and Martinez H. (1992), Subsidence history analysis and forward modeling of the Cape and Karoo Supergroups, In: M. de Wit and I. Ransome (Editors), Inversion tectonics of the Cape Fold Belt, Karoo and Cretaceous basins of southern Africa. A.A. Balkema, Rotterdam, The Netherlands. 239-249

Cole D. (1992), Evolution and development of the Karoo Basin, In: M. de Wit and I. Ransome (Editors), Inversion tectonics of the Cape Fold Belt, Karoo and Cretaceous basins of southern Africa. A.A. Balkema, Rotterdam, The Netherlands. 87-99

Cole D. and McLachlan I. (1994), Oil shale potential and depositional environment of the Whitehill formation in the main Karoo basin, SOEKOR Internal Report, No. 1994-0213.

Corner B. (1989), The Beattie anomaly and its significance for crustal evolution within the Gondwana framework, Extended Abstracts South African Geophysical Association, First Technical Meeting, 15-17.

de Beer J., van Zijl J. and Gough D. (1982), The Southern Cape Conductive Belt (South Africa): Its Composition, Origin and Tectonic Significance, Tectonophysics, $\mathbf{8 3}, 205-225$.

de Wit M. and Ransome I. (Editos) (1992), Inversion tectonics of the Cape Fold Belt, Karoo and Cretaceous basins of southern Africa. A.A. Balkema, Rotterdam, The Netherlands, 269pp.

Eglington B. and Armstrong R. (2003), Geochronological and isotopic constraints on the Mesoproterozoic Namaqua-Natal Belt: evidence from deep borehole intersections in South Africa, Precambrian Research, 125, 179-189.
Gahlan H.A., Arai S., Ahmed A.H., Ishida Y., Abdel-Aziz Y.M. and Rahimi A. (2006), Origin of magnetite veins in serpentinite from the Late Proterozoic Bou-Azzer ophiolite, Anti-Atlas, Morocco: An implication for mobility of iron during serpentinization, Journal of African Earth Sciences, 46, 318-330 Gerovska D., Araúzo-Bravo M. J., Stavrev P. (2007), Estimation of Magnetization Direction of 2.5D Bodies from the Black Sea Shelf, Bulgaria, using Reduced-to-the-Pole and Magnitude Transform Magnetic Anomalies, Extended Abstract EGM 2007 International Workshop, Capri, Italy, April 15-18, 2007. 4pp.

Gough D., de Beer J. and van Zijl J. (1973), A magnetometer array study in southern Africa, Geophysical Journal of the Royal Astronomical Society, 34, 421-433.

Guo B., Lackie M. and Flood R. H. (2004), The Subsurface Geometry of The Peel Fault from Magnetic Data north-southwest Australia, American Geophysical Union Spring Meeting Abstracts, A13+.

Hälbich I. (1983), A geodynamic model for the Cape Fold Belt., In: A. Söhnge and Hälbich I.W. (Editors), Geodynamics of the Cape Fold Belt, Geological Society of South Africa Special Publication, 12, 177-184.

Hälbich I. (1993), Cape Fold Belt -Agulhas Bank Transect across Gondwana suture, southern Africa, American Geophysical Union Special Publication, 202, 18pp.

Harvey J., de Wit M., Stankiewicz J. and Doucoure C. (2001). Structural variations of the crust in the Southwest Cape, deduced from seismic receiver functions, South African Journal of Geology, 104, 231-242.

Jacobs J., Thomas R. and Weber K. (1993), Accretion and indentation tectonics at the southern margin of the Kaapvaal craton during the Kibaran (Grenville) orogeny., Geology, 21, 203-206.

Johnson M., van Vuuren C., Visser J., Cole D., de Wickens H., Christie A. and Roberts D. (1997), The Foreland Karoo Basin, South Africa., In: R. Selley (Editor). African Basins. Sedimentary Basins of the World, Elsevier, Amsterdam, 3, 269-317.

le Roux J. (1995), Heartbeat of a mountain: diagnosing the age of depositional events in the Karoo (Gondwana) Basin from the pulse of the Cape Orogen, Geologische Rundschau, 84, 626-635.

Lindeque A.S., Ryberg T., Stankiewicz J., Weber M.H. and de Wit M.J. (2007), Seismic imaging of the crust and Moho in a section across the Beattie Magentic Anomaly, Deep crustal seismic reflection experiment across the southern Karoo Basin, South Africa. South African Journal of Geology, 110, 419-438.

Maus S. and Haak V. (2003), Magnetic field annihilators: invisible magnetization at the magnetic equator, Geophysical Journal International, 155, 509-513, doi:10.1046/j.1365-246X.2003.02053.x

Parsiegla N., Gohl K. and Uenzelmann-Neben G. (2007), Deep crustal structure of the sheared South African continental margin: first results of the Agulhas-Karoo Geoscience Transect, South African Journal of Geology, 110, 393-406.

Pitts B., Mahler M., de Beer J. and Gough D. (1992), Interpretation of magnetic, gravity and magnetotelluric data across the Cape Fold Belt and Karoo Basin, In: M. de Wit and I. Ransome (Editors), Inversion tectonics of the Cape Fold Belt, Karoo and Cretaceous basins of southern Africa. A.A. Balkema, Rotterdam, The Netherlands. 27-32.

Rasmussen R. and Pedersen L. (1979), End corrections in potential field modelling, Geophysical Prospecting, 27, 749-760.

Ritter O., Junge A. and Dawes G.J. (1998), New equipment and processing for magnetotelluric remote reference observations, Geophysical Journal International, 132, 535-548.

Ritter O., Weckmann U., Vietor T. and Haak V. (2003), A magnetotelluric study of the Damara Belt in Namibia 1. Regional scale conductivity anomalies, Physics of the Earth and Planetary Interior, 138, 71-90, doi:10.1016/S0031-9201(03)00,078-5.

Rodi W. and Mackie R.L. (2001), Nonlinear conjugate gradients algorithm for 2D magnetotelluric inversion, Geophysics, 66, 174-187.

Shive P., Blakely R., Frost B. and Fountain D. (1992), Magnetic properties of the continental lower crust, In: D.M. Fountain, R.J. Arculus, and R.W. Kay (Editors), Continental Lower Crust, Elsevier, Amsterdam, The Netherlands, 145-177.

Stankiewicz J., Ryberg T., Schulze A., Lindeque A., Weber M. and de Wit M. (2007), Initial Results from Wide-Angle Seismic Refraction Lines in the Southern Cape., South African Journal of Geology, 110, 407-418.

Swift C. (1967), A magnetotelluric investigation of an electrical conductivity anomaly in the southwestern United States, Unpublished Ph.D. thesis, 
Massachusetts Institute of Technology, Cambridge, Massachusetts, United States of America.

Thomas R., Marshal C., Du Plessis A., Fitch F., Miller J., von Brunn V. and Watkeys M. (1992), Geological studies in southern Natal and Transkei implications for the Cape Orogen, In: M. de Wit and I. Ransome (Editors) Inversion tectonics of the Cape Fold Belt, Karoo and Cretaceous basins of southern Africa. A.A. Balkema, Rotterdam, The Netherlands. 229-236.

Thomas R., Agenbacht A., Cornel D. and Moore J. (1994), The Kibaran of southern Africa: tectonic evolution and metallogeny, Ore Geology Reviews, 9, 131-160

Weckmann U., Ritter O. and Haak V. (2003), A magnetotelluric study of the Damara Belt in Namibia 2. MT phases over $90^{\circ}$ reveal the internal structure of the Waterberg Fault / Omaruru Lineament, Physics of the Earth and Planetary Interior, 138, 91-112, doi: 10.1016/S0031-9201(03)00079-1.
Weckmann U., Magunia A. and Ritter O. (2005), Effective noise separation for magnetotelluric single site data processing using a frequency domain selection scheme, Geophysical Journal International, 161, 635-652, doi:10.1111/j.1365-246X.2005.02,621.x.

Weckmann U., Ritter O., Jung A., Branch T. and de Wit M. (2007), Magnetotelluric measurements across the Beattie magnetic anomaly and the Southern Cape Conductive Belt, South Africa, Journal of Geophysical Research, 112, doi: 10.1029/2005JB003975.

Wiese H. (1962), Geomagnetische Tiefentellurik Teil II: Die Streichrichtung der Untergrundstrukturen des elektrischen Widerstandes, erschlossen aus geomagnetischen Variationen, Geofisica Pura e Appicata, 52, 83-103.

Editorial handling: M. J. de Wit and Brian Horsfield. 